\title{
Genome-wide identification and expression analysis of AP2/ERF transcription factors in sugarcane (Saccharum spontaneum L.)
}

Peiting $\mathrm{Li}^{1 \dagger}$, Zhe Chai ${ }^{2 \dagger}$, Pingping Lin ${ }^{1}$, Chaohua Huang ${ }^{1}$, Guoqiang Huang ${ }^{1}$, Liangnian $\mathrm{Xu}^{1}$, Zuhu Deng ${ }^{1}$, Muqing Zhang ${ }^{2^{*}}$ (D) Yu Zhang ${ }^{3^{*}}$ and Xinwang Zhao ${ }^{1,24^{*}}$

\begin{abstract}
Background: APETALA2/ETHYLENE RESPONSIVE FACTOR (AP2/ERF) transcription factors play essential roles in plant growth, development, metabolism, and responses to biotic and abiotic stresses. However, few studies concerning AP2/ERF genes in sugarcane which are the most critical sugar and energy crops worldwide.

Results: A total of 218 AP2/ERF genes were identified in the Saccharum spontaneum genome. Phylogenetic analysis showed that these genes could be divided into four groups, including 43 AP2s, 160 ERFs and Dehydration-responsive element-binding (DREB) factors, 11 ABI3NPS (RAV), and four Soloist genes. These genes were unevenly distributed on 32 chromosomes. The structural analysis of SSAP2/ERF genes showed that 91 SSAP2/ERFs lacked introns. Sugarcane and sorghum had a collinear relationship between 168 SSAP2/ERF genes and sorghum AP2/ERF genes that reflected their similarity. Multiple cis-regulatory elements (CRES) present in the SSAP2/ERF promoter were related to abiotic stresses, suggesting that SsAP2/ERF activity could contribute to sugarcane adaptation to environmental changes. The tissue-specific analysis showed spatiotemporal expression of SSAP2/ERF in the stems and leaves of sugarcane at different development stages. In ten sugarcane samples, 39 SsAP2/ERFs were not expressed, whereas 58 SsAP2/ERFs were expressed in all samples. Quantitative PCR experiments showed that SsERF52 expression was up-regulated under salt stress, but suppressed under dehydration stress. SsSoloist4 had the most considerable upregulation in response to treatment with the exogenous hormones ABA and GA. Within $3 \mathrm{~h}$ of ABA or PEG6000 treatment, SsSoloist4 expression was up-regulated, indicating that this gene could play a role in the responses to ABA and GAassociated dehydration stress. Analysis of AP2/ERF gene expression patterns under different treatments indicated that SSAP2/ERF genes played an essential role in dehydration and salt stress responses of S. spontaneum.

(Continued on next page)
\end{abstract}

\footnotetext{
*Correspondence: mqzhang@ufl.edu; zmuqing@163.com;

yuzhang@fafu.edu.cn; zhxinwang@126.com

${ }^{+}$Peiting Li and Zhe Chai contributed equally to this work.

${ }^{2}$ State Key Laboratory for Conservation and Utilization of Subtropical

Agro-Biological Resources \& Guangxi Key Laboratory for Sugarcane Biology,

Guangxi University, Nanning 530005, China

${ }^{3}$ Fujian Provincial Key Laboratory of Plant Functional Biology, College of Life

Sciences, Fujian Agriculture and Forestry University, Fuzhou 350002, China

${ }^{1}$ National Engineering Research Center for Sugarcane \& Guangxi Key

Laboratory for Sugarcane Biology, Fujian Agriculture and Forestry University,

Fuzhou 350002, China

Full list of author information is available at the end of the article
}

(c) The Author(s). 2020 Open Access This article is licensed under a Creative Commons Attribution 4.0 International License, which permits use, sharing, adaptation, distribution and reproduction in any medium or format, as long as you give appropriate credit to the original author(s) and the source, provide a link to the Creative Commons licence, and indicate if changes were made. The images or other third party material in this article are included in the article's Creative Commons licence, unless indicated otherwise in a credit line to the material. If material is not included in the article's Creative Commons licence and your intended use is not permitted by statutory regulation or exceeds the permitted use, you will need to obtain permission directly from the copyright holder. To view a copy of this licence, visit http://creativecommons.org/licenses/by/4.0/ The Creative Commons Public Domain Dedication waiver (http://creativecommons.org/publicdomain/zero/1.0/) applies to the data made available in this article, unless otherwise stated in a credit line to the data. 
(Continued from previous page)

Conclusions: In this study, a total of 218 members of the AP2 / ERF superfamily were identified in sugarcane, and their genetic structure, evolution characteristics, and expression patterns were studied and analyzed. The results of this study provide a foundation for future analyses to elucidate the importance of AP2/ERF transcription factors in the function and molecular breeding of sugarcane.

Keywords: Sugarcane, Transcription factor, AP2/ERF gene, Abiotic stress

\section{Background}

Unfavorable environmental conditions have severe impacts on crop yields, and thus strategies to improve crop survival under adverse conditions are needed [1]. Plants respond to environmental stresses via complex regulatory mechanisms that elicit a series of physiological and biochemical responses [2]. Transcription factors play an essential role in converting stress-induced signals into cellular responses. When various abiotic stresses stimulate plants, signaling pathways involving molecules such as abscisic acid and ethylene are activated [3]. This activation is often associated with changes in the expression of transcription factors, which specifically bind to transacting elements in promoter regions at downstream target genes. For cis-acting elements, the regulatory effect is executed through the activation or inhibition of downstream functional genes [4]. In plants, these two main processes are involved in responses to biotic or abiotic stress, which are mediated by various transcription factors. The AP2/EREBP (APETALA2/ethylene response element-binding protein) superfamily comprises a large class of transcription factors in plants. Multiple studies have demonstrated that AP2/ERF transcription factors in plants are essential for stresses responses, and their expression is regulated by plant hormones $[5,6]$. In response to stresses in plants, AP2/ERF transcription factors' expression is regulated to coordinate growth under stresses [7].

AP2/ERF family members contain the highly conserved AP2/ERF DNA binding domain. Based on sequence similarities and the number of AP2/ERF domains, the AP2/ERF superfamily can be divided into four categories: AP2, ERF (Ethylene-responsive factor), RAV (related to ABI3/VP1), and Soloist [8]. In most cases, the AP2 family contains proteins with two AP2/ ERF domains involved in regulating plant developmental processes [9]. RAV proteins contain two different DNAbinding domains (AP2 and B3), which are regulated by ethylene or brassinosteroid hormones and also are involved in biotic and abiotic stress responses [10, 11]. The ERF family is divided into two subfamilies: ERF and DREB (dewater-responsive element binding). Both ERF and DREB contain only one AP2/ERF domain and are critical regulators of plant responses to biotic and abiotic stresses [12]. The Soloist group contains only one AP2 conserved domain and forms a separate group based on its significant structural difference from the other AP2/ ERF family members. However, there are limited evidence that the Soloist group members are positive regulators of SA-mediated plant defense against pathogens [13].

AP2/ERF transcription factors have well-documented functions in plant growth and development. For example, in Arabidopsis thaliana, WIND1 (RAP2.4, At1g78080) is involved in controlling cell dedifferentiation that, in turn, affects proliferation, axillary bud growth, and bud branching [14]. The ERF family gene $O S E A T B$ in rice limits internode elongation by downregulating gibberellin biosynthesis genes [15]. In tomatoes [16], grapes [17], Chinese jujube [18], and bananas [19], some AP2/ERF superfamily members are involved in fruit maturation.

AP2/ERF transcription factors also play a crucial role in abiotic stress responses in plants. For example, OsER$E B P 1$ and OsEREBP2 modulate the expression of $O S R M C$, a negative regulator of rice salt stress [20]. Overexpression of maize $\mathrm{ZmDBP3}$ enhances tolerance of transgenic Arabidopsis to drought and cold stresses [21]. In contrast, overexpression of the WIN1 gene from Sorghum confers drought resistance to Arabidopsis by regulating the epidermis [22]. The ERF and DREB families, in particular, contain members that have excellent performance in response to abiotic stress. The DREB protein can specifically bind the A/GCCGAC (DRE/CRT) element related to genes involved in responses to ABA, drought, and low temperature, while ERF subfamily members can interact with the core sequence AGCC GCC (GCC-box) of the ethylene response element (ERE). Such binding to ERE element regulates responses to ethylene and abiotic stresses, and promotes disease resistance [23]. However, many reports suggest that both Arabidopsis ERF and DREB can be combined with DRE/ CRT or ERE elements, indicating that they have a potential role in abiotic [24]. DREBs belong to the ABAindependent signal transduction pathway and are divided into two subclasses: DREB1/CBF and DREB2. DREB1/ $C B F$ genes are thought to be involved mainly in lowtemperature sensation, whereas most DREB2 genes participate in response to water or heat shock stress [25]. However, there is increasing evidence that the stress 
regulation mediated by the $D R E B 1 / C B F$ and $D R E B 2$ genes is species-specific [26]. AP2/ERF transcription factors are also likely to be essential mediators of plant resistance, but few studies concern these genes' activity in sugarcane.

Sugarcane (Saccharum spp.) is the most important crop for sugar and biofuel [27]. Sugarcane provides 75 and $40 \%$ of global sugar and ethanol production [27, 28]. Damage to sugarcane caused by environmental stresses thus can have substantial economic impacts [29]. Drought stress during sugarcane growth reduces productivity by between 30 and $70 \%$, and minimizes sucrose formation and sucrose recovery by $5 \%$ [30]. Genomewide analysis of the presence of AP2/ERF transcription factors in wild sugarcane Saccharum spontaneum species would be necessary for sugarcane resistance research. In this study, we identified members of the AP2/ERF superfamily in the $S$. spontaneum genome. We also carried out the phylogenetic relationships, gene structure, conserved domains, promoters, chromosomal location distribution, and gene duplication. The effects of $A P 2 / E R F$ genes on sugarcane adaptation to environmental stresses were analyzed to enhance our understanding of the mechanisms.

\section{Results}

\section{Identification and classification of AP2/ERF genes}

A total of 218 complete $A P 2 / E R F$ genes were identified in the sugarcane genome database. The identified genes ranged from 416 to $22,786 \mathrm{bp}$ and were predicted to encode proteins with 127-876 amino acids (aa) (Additional files 1 and 2). Based on sequence similarities and the number of conserved AP2 domains (Additional files 3 and 4), the AP2/ERF genes were divided into four families: AP2, ERF, RAV, and Soloist. The AP2 family had 43 genes, of which 36 had two identical conserved AP2 domains, and 7 had only one conserved AP2 domain (SsAP2-37 to SsAP2-43). The ERF family had 160 genes, 59 and 101 were assigned to DREB (SsDREB1 to SsDREB59) and ERF (SsERF1 to SsERF101) subfamily. The RAV family comprised of 11 members (SsRAV1 to SsRAV11) with conserved AP2 and B3 domains. Another four genes (SsSoloist1 to SsSoloist4) with one or two conserved AP2 domain had less similarity to ERF or AP2. Instead, these four genes had higher homology to Arabidopsis At4g13040, and thus were classified into the Soloist. Because no reliable naming method was defined in previous research on the AP2/ ERF family, our naming convention was based on the grouping of 218 sequences and their chromosomal positions. The total number of AP2/ERF superfamily candidate genes in sugarcane was higher than that in the Arabidopsis (147) and rice (181) [8]. However, the number of ERF family members was similar but slightly higher (122 and 145 for Arabidopsis and rice, respectively).

\section{Phylogenetic analysis}

To analyze the evolutionary relationship of the SsAP2/ $E R F$ genes, we constructed phylogenetic trees based on the amino acid sequences encoded by these genes (Fig. 1). The phylogenetic tree clustered all of the SsAP2/ERF genes into four main branches: AP2, ERF, RAV, and Soloist. According to the classification criteria in Arabidopsis and rice [8], the ERF family was divided into two subfamilies: the DREB subfamily (59 members, divided into groups I, II, III, and IV, containing 19, 11, 19 , and 10 members, respectively) and the ERF subfamily (101 members divided into groups V, VI, VII, VIII, IX, $\mathrm{X}$, and XIV containing 12,11,12, 18, 24, 16 and 8 members, respectively) (Fig. 2). Notably, most species lacked a XIV group, although Os08g41030 in rice had a conserved domain similar to these eight sugarcane members and could be classified into the XIV group. Arabidopsis had no genes that were consistent with the XIV group. Thus, an additional examination is needed to determine whether functional differentiation occurred and its significance.

\section{Gene structure and conserved motif analysis}

To characterize the structural diversity of SsAP2/ERF genes, we analyzed the number of introns and exons and the distribution of conserved domains in the coding sequence of a single SsAP2/ERF gene (Additional file 5: Figure S6). Through gene structure analysis, differences during the AP2, ERF, and RAV families could be observed, and the results from the conserved domain analysis were consistent with those of previous studies. The number of introns among the different family genes varied markedly (Fig. 3), and $42 \%$ of AP2/ERF genes had no intron. Most of DREB genes had no intron except for 18 genes, such as SsDREB16, SsDREB20, SsDREB49, $S s D R E B 50$, which the number of introns ranged from 1 to 24. A total of 40 ERF genes had no intron. Unlike the ERF genes, 42 AP2 genes had the number of introns ranging from 2 to 9. For the 11 RAV genes, SsRAV9 had one intron, SsRAV5 had six introns, while the remaining nine RAV genes had on intron. The number of introns of the four Soloist genes was between 6 and 9. Interestingly, the genes clustered into the same branch on the phylogenetic tree had similar exon-intron structure. For example, DREB group II genes had no intron except the gene SsDREB33, which had only one intron.

We used MEME to investigate SsAP2/ERF gene diversity further and predicted the presence of 25 conserved motifs in the AP2/ERF family (Additional file 6 and Figure 3). Motif-1 and -2 were present in all SsAP2/ERF 


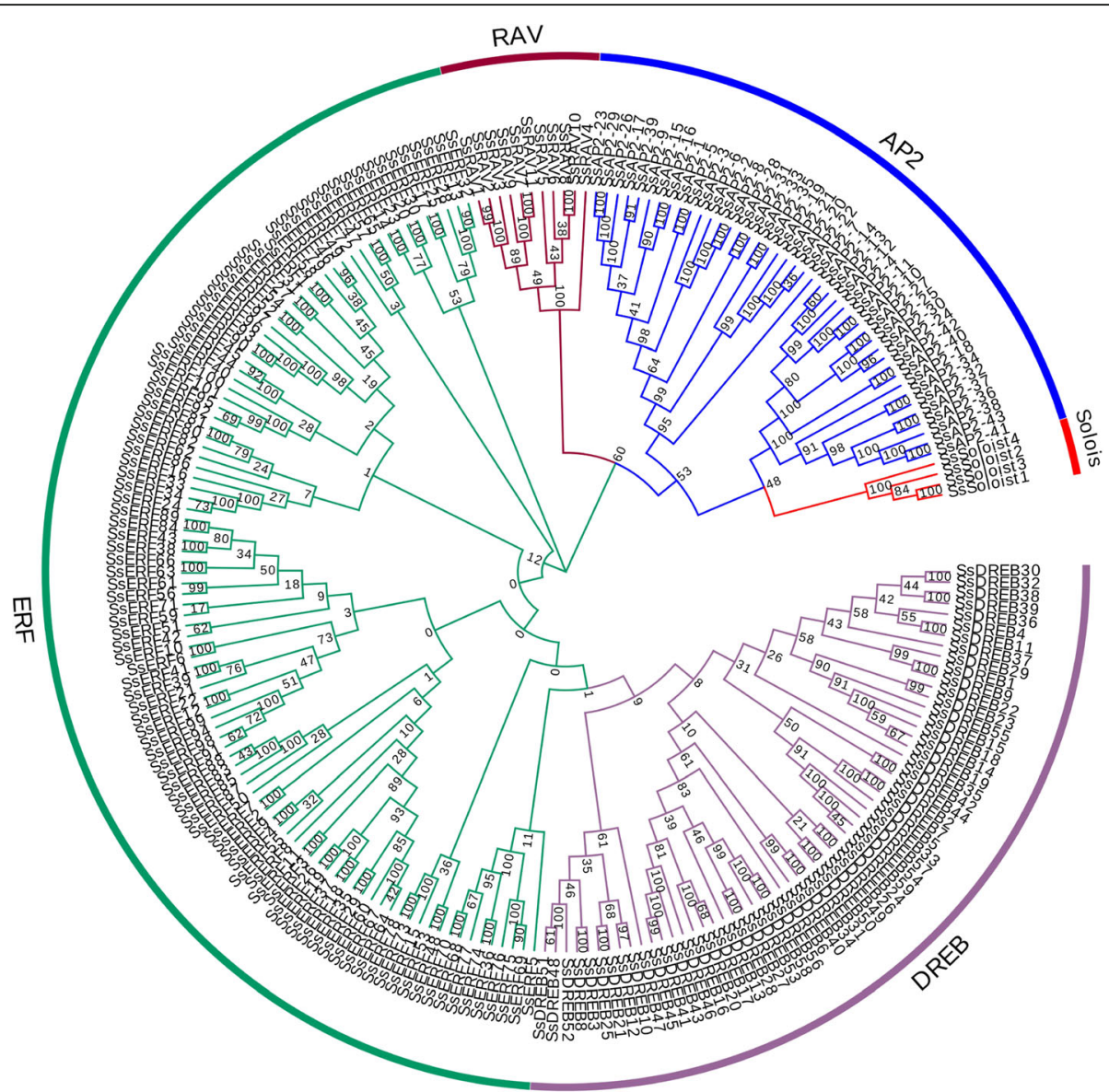

Fig. 1 Phylogenetic tree of AP2/ERF genes in sugarcane. ERF, DREB, AP2, RAV, Soloist families were presented in different colors

protein sequences; Both motif- 3 and -4 were available in most members of the AP2, ERF, DREB, and RAV subfamily; Motif-6, $-7,-8,-20$, and -22 were found only in the AP2 family; Motif-10, -12 and -15 appeared in group I; Motif-13 appeared in group XIV, and Motif-9 and -11 were unique to the RAV family. We also found that Motif-1, -2 , and -7 existed in the AP2 conserved domain, whereas Motif- $9,-11$, and -16 were located in the B3 domain (Fig. 3). As expected, most close relatives among subfamily members had similar motif compositions, suggesting that AP2/ERF proteins within the same subfamily were functionally identical.

\section{Chromosome distribution}

The 218 identified SsAP2/ERF genes were mapped to 32 chromosomes, and the distribution across the chromosomes varied widely (Fig. 4). Chr2A had the most genes (12), whereas Chr6C and Chr8C had only three genes (Additional file 7). At least one of the 59 SsDREB and 101 SsERF genes could be found on each of the 32 chromosomes, and the four Soloist genes were distributed on four homologous chromosomes, Chr4A, Chr4B, Chr4C, and Chr4D. Members of the SsRAV family were present only on chromosomes 3 and 7. Surprisingly, $50 \%$ of the SsAP2/ERF genes localized at one of the four rearrangement chromosomes (SsChr02, SsChr05, SsChr06 and SsChr07) and nine SsAP2/ERF genes were present in the rearranged regions, including SsChr5 (Sb05S) 57.6-89.1 Mbp, SsChr6 (Sb05L) 54.6-90.6 Mbp, SsChr7 (Sb08S) 62.0-83.3 Mbp, SsChr2 (Sb08L) 98.5-125.9 Mbp [31].

\section{Gene duplication analysis}

Multiple studies indicated that gene families evolved due to genome-wide duplication, segmental duplication or tandem duplication, and gene diversification occurred after these duplication events [32]. To explore SsAP2/ $E R F$ genes evolution, we studied tandem and segmental duplication events of these genes using chromosomal information for S. spontaneum (Additional file 8). A total of eight pairs of tandem duplication genes were detected, of which two pairs were $R A V$ genes, and six ones were ERF genes (Fig. 4). Three genes, SsRAV4, SsRAV5, and SsRAV6, were two tandem duplication gene pairs located on the same chromosome and adjacent to each other. Besides, 70 pairs of 103 SsAP2/ERF segmental duplication genes were detected (Fig. 5). Among these, 53 


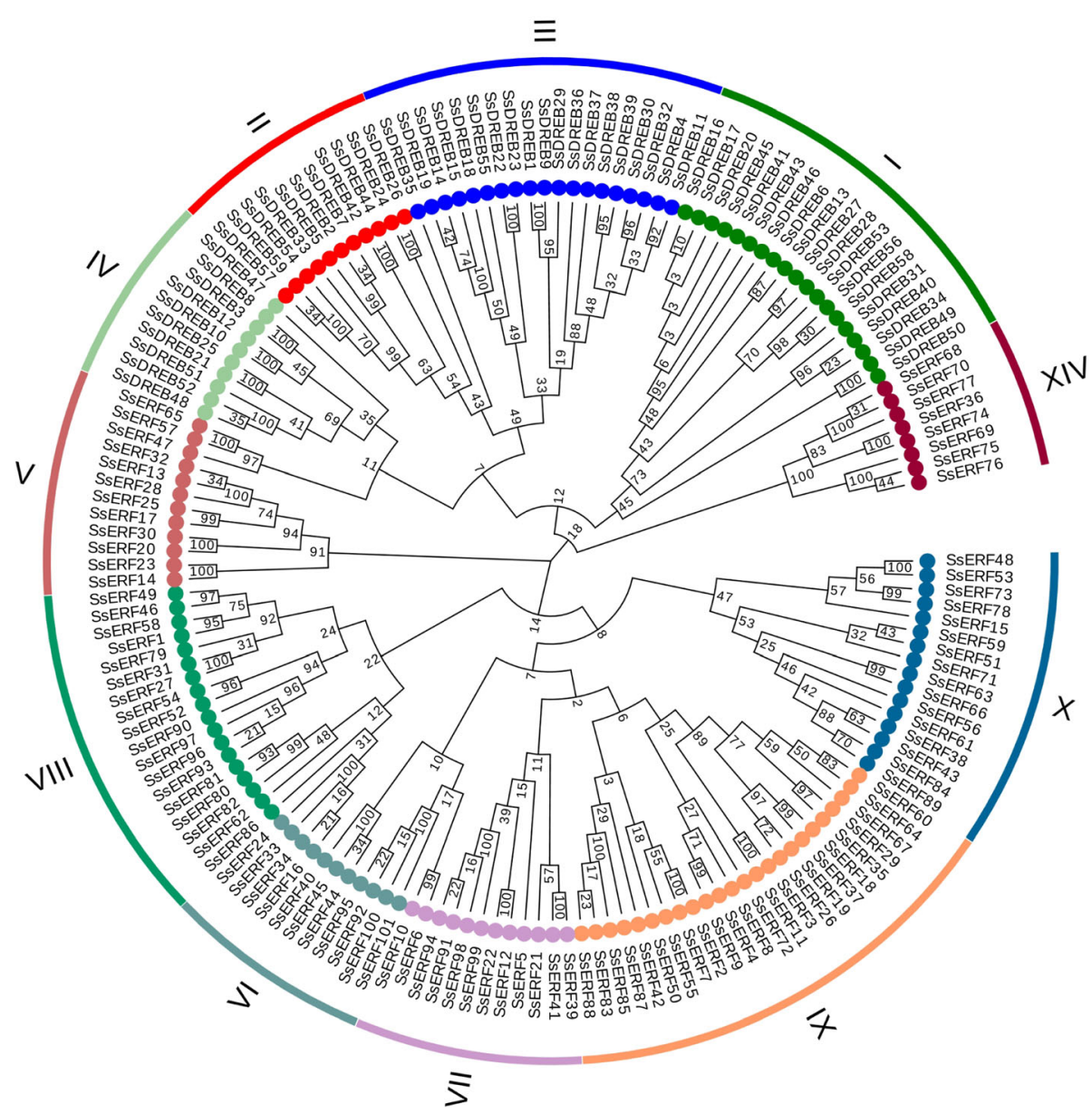

Fig. 2 Phylogenetic tree of ERF and DREB subfamily genes in sugarcane. Each group has a different color. The 11 clades (I-XIV) of the ERF and $D R E B$ subfamily genes were divided according to previous classifications in Arabidopsis and rice

occurred between alleles, and 17 were between nonalleles. There were four pairs of SsAP2/ERF segmental duplication gene pairs distributed on Chr4 and Chr5. The distribution might be due to the segments of both Chr4 and Chr5 chromosomes from the ancestral A4 chromosome [31].

The time for the divergence of the SsAP2/ERF genes was estimated to have undergone tandem and segmental duplication based on Ks values (Additional file 8). The divergence time for the eight SsAP2/ERF tandem duplication pairs ranged from 14.2 to 104.2 million years ago (mya), illustrating that these SsAP2/ERFs arose from recent gene duplication events in $S$. spontaneum. Sixtyfour segmental duplication pairs appeared earlier, based on a divergence time that ranged from 4.9 to 89.9 mya, whereas the other four segmental duplication pairs were ancient, diverging between 164.7 and 212.1 mya.

We calculated $\mathrm{Ka} / \mathrm{Ks}$ values for SsAP2/ERF genes in tandem and segmental duplications to detect which selection type promoted $A P 2 / E R F$ gene family evolution (Additional file 8 ). The $\mathrm{Ka} / \mathrm{Ks}$ ratio of tandem duplication gene pairs among $A P 2 / E R F$ genes ranged from 0.17 to 1.24 , with an average of 0.57 . Tandem duplication gene pairs having a $\mathrm{Ka} / \mathrm{Ks}$ ratio $<1$ accounted for $89 \%$ of the genes tested. The $\mathrm{Ka} / \mathrm{Ks}$ ratio for segmental duplication gene pairs ranged from 0 to 2.6, with an average of 0.62 , and $92 \%$ of pairs had $\mathrm{Ka} / \mathrm{Ks}<1$. These results indicated that repetitive SsAP2/ERF genes were under intense purification selection pressure, and the duplication-producing gene had enormously evolved and maintained its functional stability. Meanwhile, nine replicate gene pairs had $\mathrm{Ka} / \mathrm{Ks}>1$, indicating that they were subject to positive selection after duplication differentiation.

\section{Evolutionary analysis of SsAP2/ERFs and other plant AP2/ ERFs}

A syntenic map of five representative species was constructed to examine the evolutionary origin of the AP2/ $E R F$ genes in sugarcane (Fig. 6 and Additional file 9). A total of 168 SsAP2/ERF genes were synonymous with genes in Sorghum, followed by rice (151), wheat (145), 


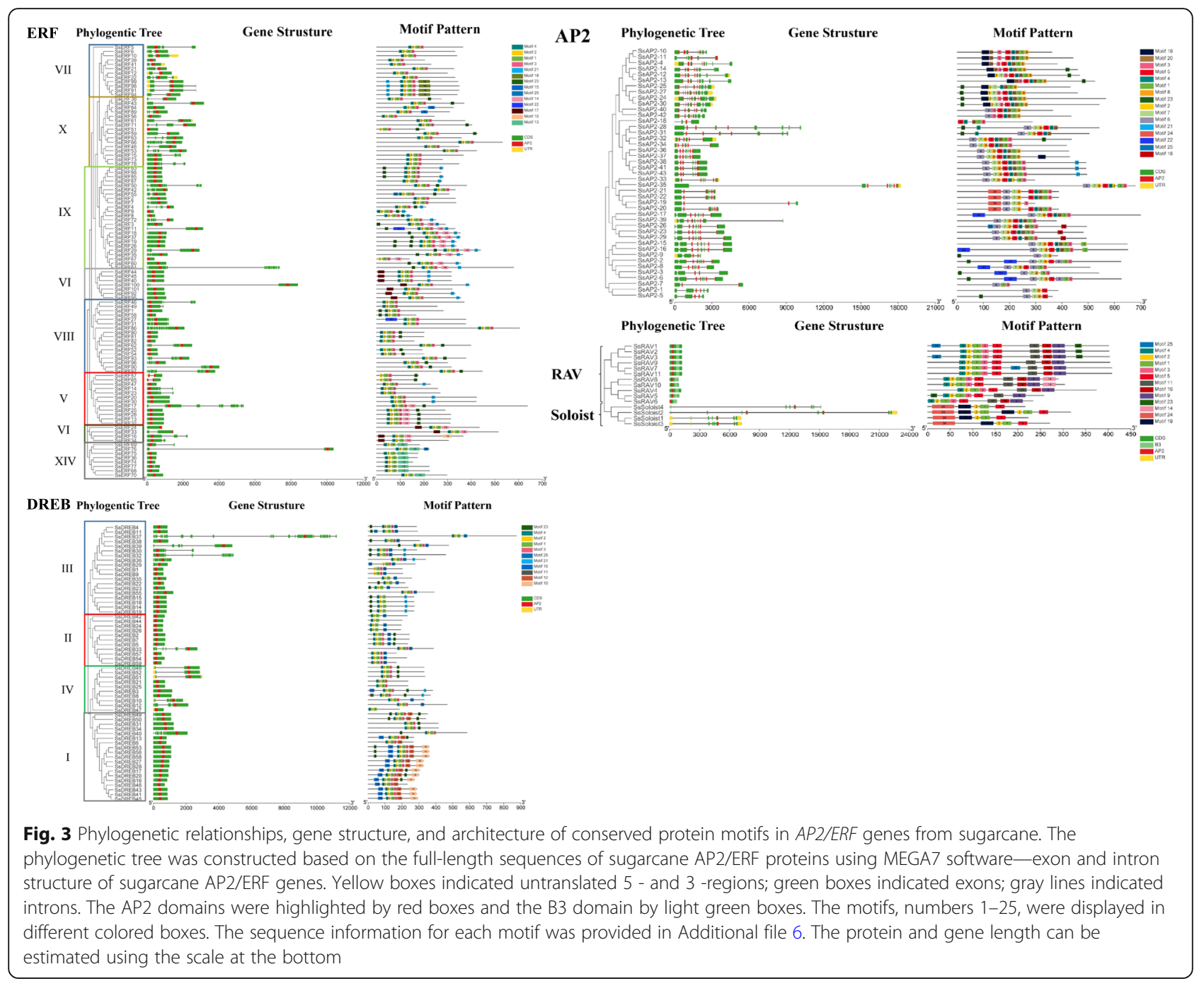

maize (143), and Arabidopsis (19). Orthologous gene pairs were distributed across all chromosomes of $S$. spontaneum. Some SsAP2/ERF genes were associated with at least three pairs of corresponding genes (particularly $A P 2 / E R F$ genes in sugarcane and wheat), suggesting that these genes played an essential role in SsAP2/ERF superfamily evolution. Interestingly, some collinear gene pairs (90 SsAP2/ERF genes) were available in monocotyledonous plants (sugarcane and rice/sorghum/wheat/ maize), but absent in the dicotyledonous ones (sugarcane and Arabidopsis).

\section{Analysis of putative cis-regulatory elements (CREs)}

CRE is a non-coding DNA sequence that regulates transcription in a defined temporal/spatial expression pattern. CREs are essential for understanding expression differences and mutations. We used PlantCare to identify putative CREs of $2000 \mathrm{bp}$ located on SsAP2/ERF genes (Fig. 7 and Additional file 10). These CREs were classified according to their function, and the number of
CRE in each sequence was determined. Many CREs responded to different hormone inducers, such as abscisic acid (ABA), salicylic acid (SA), methyl jasmonate (MeJA), gibberellin (GA), and auxin. Among them, ABA and MeJA response elements were the most common. There are also CREs genes related to various stress stimuli (such as a wound, defense, and stress, anoxic, anaerobic, and low-temperature). A total of 182 SsAP2/ERF genes contained the abscisic acid response element, 126 genes with the gibberellin response element, and 192 genes with the MeJA response element. Another 108 SsAP2 / ERF genes contained low-temperature response elements, while 155 genes had light responsiveness elements. Each family had ten types of CREs, including light responsiveness, endosperm expression, anoxic specific inducibility, auxin, gibberellin, abscisic acid, MeJA, and salicylic acid responsiveness, MYBHv1, and MYB binding site. DREB genes had the most CREs species, among which alpha-amylase promoters and root-specific CREs only existed in DREB subfamily genes. The CREs 


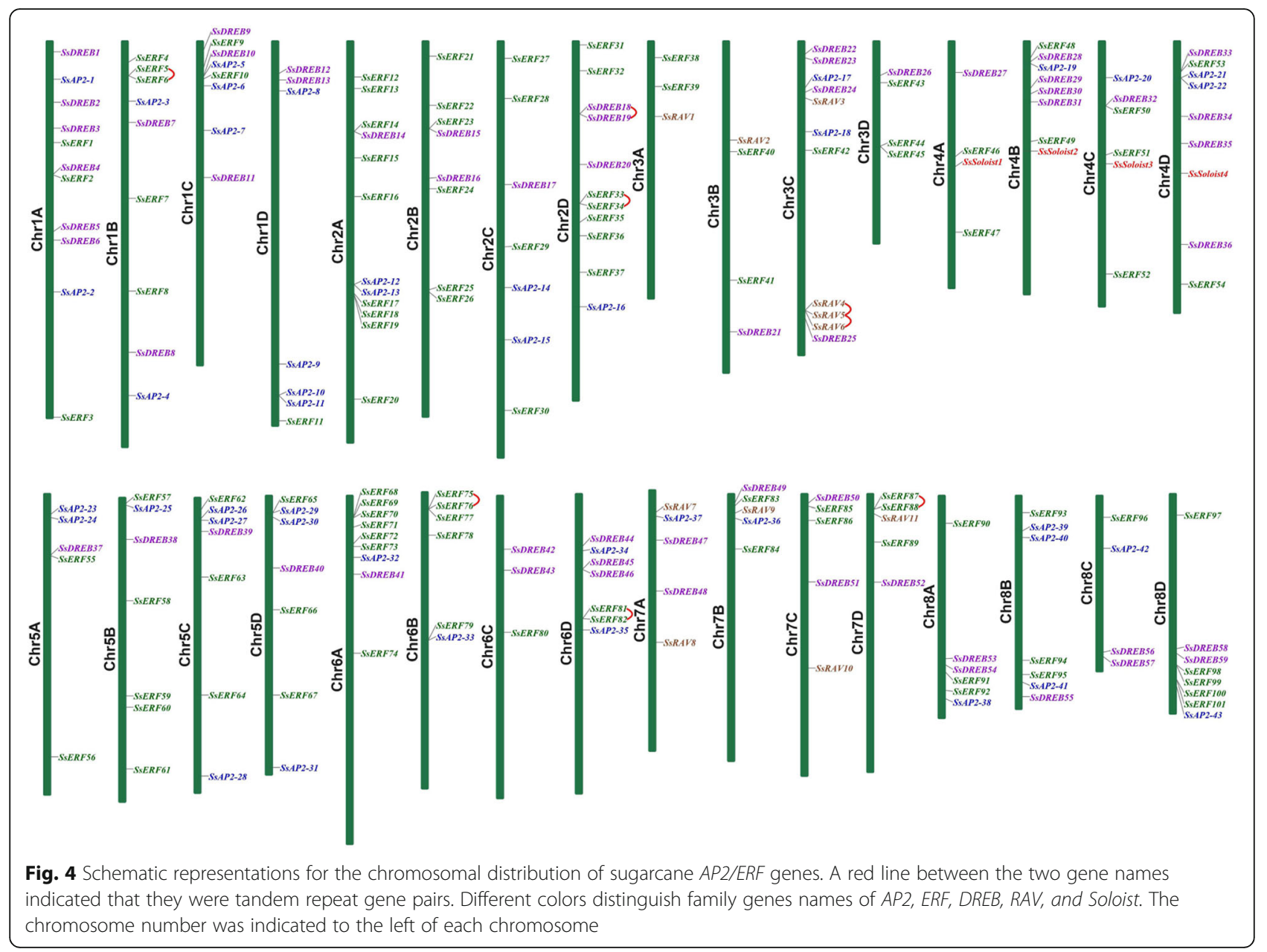

of Soloist family genes were the least, mainly hormone and stress response. The five families of genes had similar CREs types, but the number of copies of each CRE was different. In some $A P 2 / E R F$ genes, the promoter region contained cis-acting elements for various transcription factors, such as MYB, MYC, ERE and DRE elements.

\section{Expression pattern of $A P 2 / E R F$ genes during sugarcane development}

To understand specific spatiotemporal expression patterns of SsAP2/ERF genes, we analyzed the identified genes' expression profiles in ten different tissues and at different developmental stages using publicly available gene expression data (Additional files 11 and 12). Among the SSAP2/ERF genes examined, 39 were not expressed in all tissue samples, 58 were expressed in all ten tissue types (FPKM $>0$ ), and 27 were constitutively expressed (FPKM $>2$ ). Total 19 genes in DREB group I was all expressed in at least one sample, among which SsDREB17, SsDREB27, and SsDREB28 were highly expressed in all ones, indicating that these group I members were likely essential functional genes. The expression levels of $26 S s A P 2 / E R F$ genes increased during leaf maturation, suggesting that they might play an important role in leaf growth and development. The expression of SsDREB38, SsERF91, SsERF98, SsERF39, and SsERF99 in stems was much higher than that in leaves in the three developmental stages. Among them, four ERF genes belonged to ERF group VII, indicating that they played an essential role in cane stems. Expressions of 11 genes, including SsDREB56, SsDREB48, SsERF15, and SsRAV3, SsSoloist1, and SsSoloist2, were higher in the three stages of leaf development than those in the stems, indicating that these genes played an important role in leaf development. The expression of ten genes, including SsDREB55, SsERF62, and SsERF54 in different tissues in the pre-mature and mature stages, was higher than that seen in various tissues in the seedling stage. Among these genes, many were in the ERF subfamily, indicating that they played an essential role in the mature sugarcane stage. 


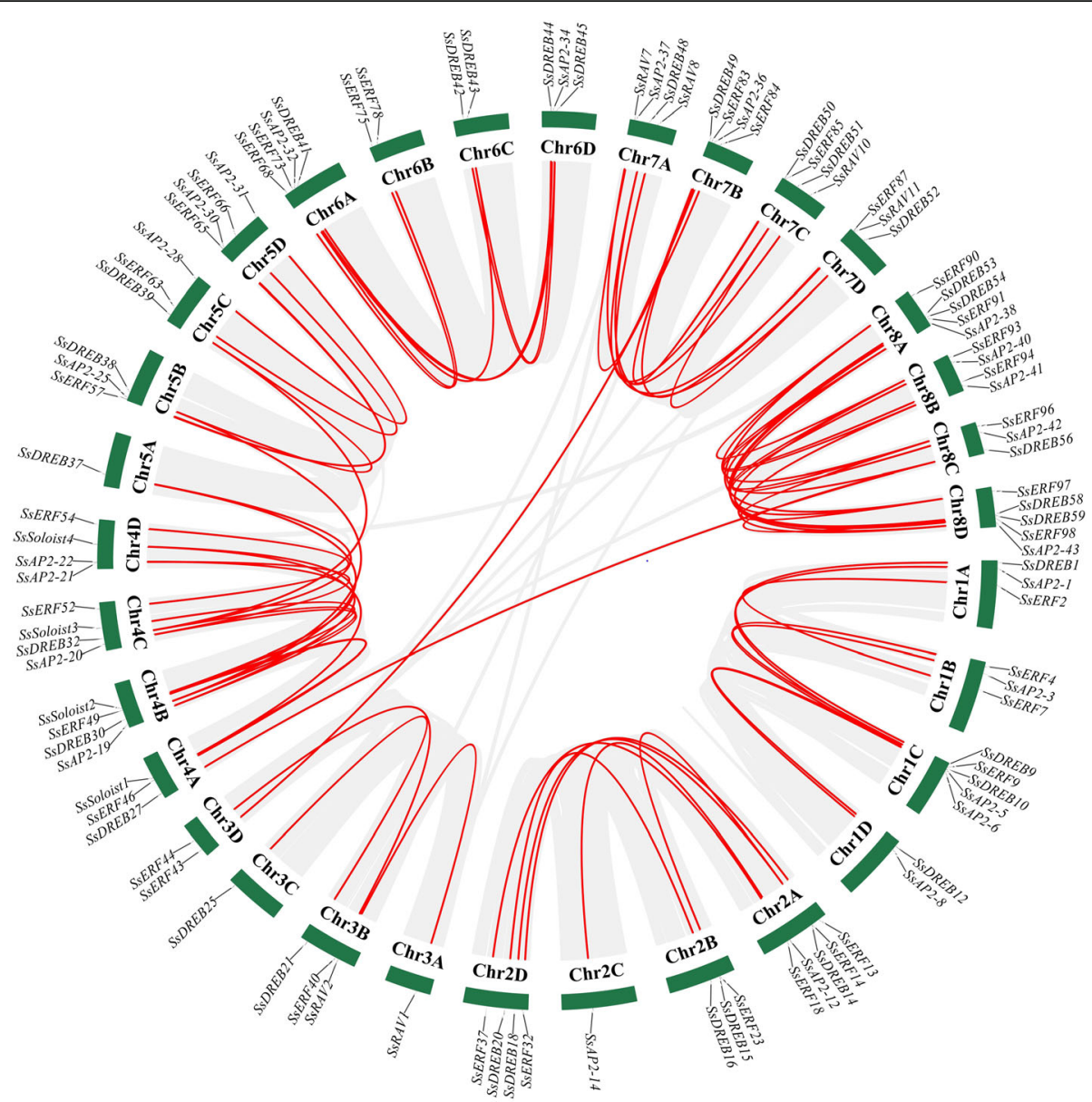

Fig. 5 Schematic representations for the interchromosomal relationships of sugarcane AP2/ERF genes. Gray lines indicated all syntenic blocks in the sugarcane genome, and the red lines indicated duplicated AP2/ERF gene pairs

\section{Expression analyses of SsAP2/ERF genes in response to} abiotic stress and hormone treatments

To further confirm whether SsAP2/ERF gene expression was affected by different abiotic stresses and hormone treatments, we examined 12 genes from five families. We analyzed their expression patterns following different treatments (Fig. 8 and Additional file 13). $\mathrm{NaCl}$, PEG6000, and ABA treatment could induce the expression of all 12 genes. After $3 \mathrm{~h}$ of treatment, compared with the control group simultaneously, the up-regulation multiple was the highest among all treatment time points. Different treatments had varying degrees of influence on gene expression. Compared with the control group, all the genes were induced by $\mathrm{NaCl}$, except that SsSoloist4 down-regulated expression at $72 \mathrm{~h}$ of $\mathrm{NaCl}$ treatment. The up-regulation multiple was significantly higher than the other three treatments. Some genes had opposite expression patterns under different treatments. For example, SsERF52 was down-regulated at 1, 6, and $12 \mathrm{~h}$ after PEG6000 treatment. Although SsERF52 was up-regulated 2.15 times at $3 \mathrm{~h}$, its up-regulation was significantly lower than that of other genes at $3 \mathrm{~h}$. Meanwhile, the expression of SsERF52 was induced by salt stress at six treatment times. The up-regulated multiple was 15.21 times at $3 \mathrm{~h}$, which was significantly higher than other genes, indicating that the response of SsERF 52 to salt stress and dehydration stress was different. The other four genes, SsAP2-25, SsDREB25, SsRAV11, and $S s R A V 4$, had no significant up-down multiple changes at all time points after GA treatment but were induced by the other three treatments.

\section{Discussion}

As one of the largest gene families in plants, the AP2/ ERF family plays a vital role in multiple physiological and biochemical processes by regulating the expression of genes that participate in response to various stress conditions in Arabidopsis, rice [8], maize [33], poplar [34], and grapes [17]. Still, there is limited information concerning the regulation and structure of these genes in sugarcane. In this study, we examined whole-genome data for the wild sugarcane species S. spontaneum to 


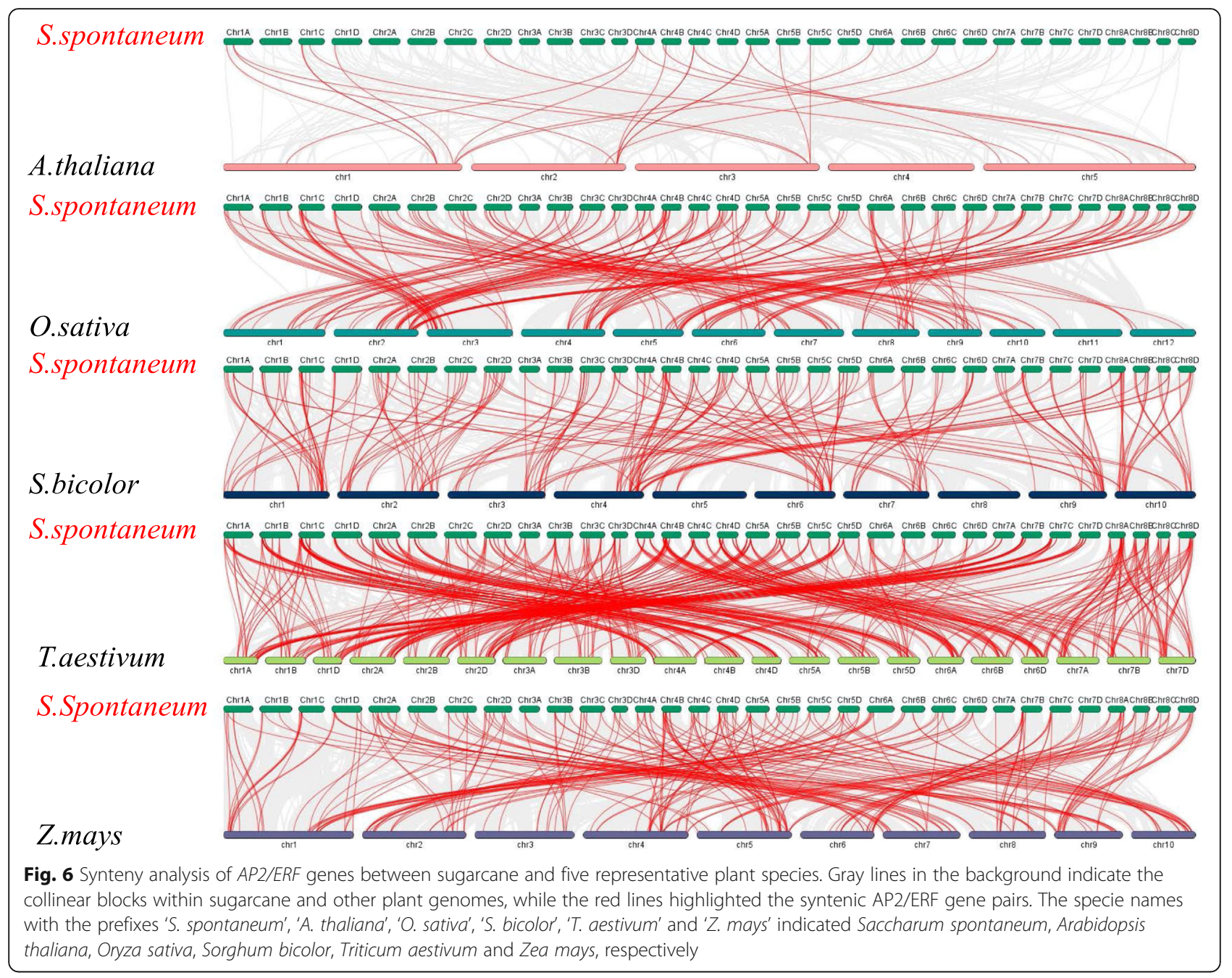

identify genes encoding AP2/ERF family transcription factors, and to analyze their roles based on published expression data for S. spontaneum tissue and qRT-PCR results.

Genome-wide analysis of sugarcane identified 218 SsAP2/ERF genes, which was higher than that in rice (164) [8], wheat (117) [35], and Arabidopsis (145) [8], but fewer than that for maize (292) [33]. The genome size varies in different plants, rice $(466 \mathrm{Mb})$, wheat (4.94 Gb), Arabidopsis (125 Mb), maize (2.3 $\mathrm{Gb})$, and $S$. spontaneum (3.36 Gb), indicating that the number of AP2/ERF superfamily members is relatively stable and does not have an absolute correlation with genome size. However, since AP85-441 $(1 \mathrm{n}=4 \mathrm{x}=32)$ used to sequence the $S$. spontaneum genome was haploid and produced from the culture of the octoploid SES208, the number of AP2/ERF genes in octoploid S. spontaneum could be over 218 [31]. Gene duplication plays a vital role in gene family amplification to generates gene clusters or hotspots via tandem repetitive and segmental duplication to produce homologous genes that expand the total number of genes. Segmental duplication events found in 104 SsAP2/ERF genes also validated this possibility. S. spontaneum has undergone two Whole Genome Duplication (WGD) events overtime in which its homologous chromosomes underwent duplication from one to two and then to four [31]. SsAP2/ERF gene repeats likely occurred during these two WGDs. We also found evidence that purification selection was the main driving force behind the SsAP2/ERF gene family's evolution. By evaluating the gene structure of $A P 2 / E R F \mathrm{TF}$, all SsAP2 and SsSoloist genes had introns, whereas 50.6 and $83.3 \%$ of SSERF/DREB and SsRAV genes, respectively, had no introns. Loss of introns in genes after segmental duplication occurred more rapidly than intron acquisition [36]. Also, some studies showed that the number and distribution of introns were related to plant evolution [37], such that introns might have been lost from ERF and RAV family genes during the evolution of higher plants. From 


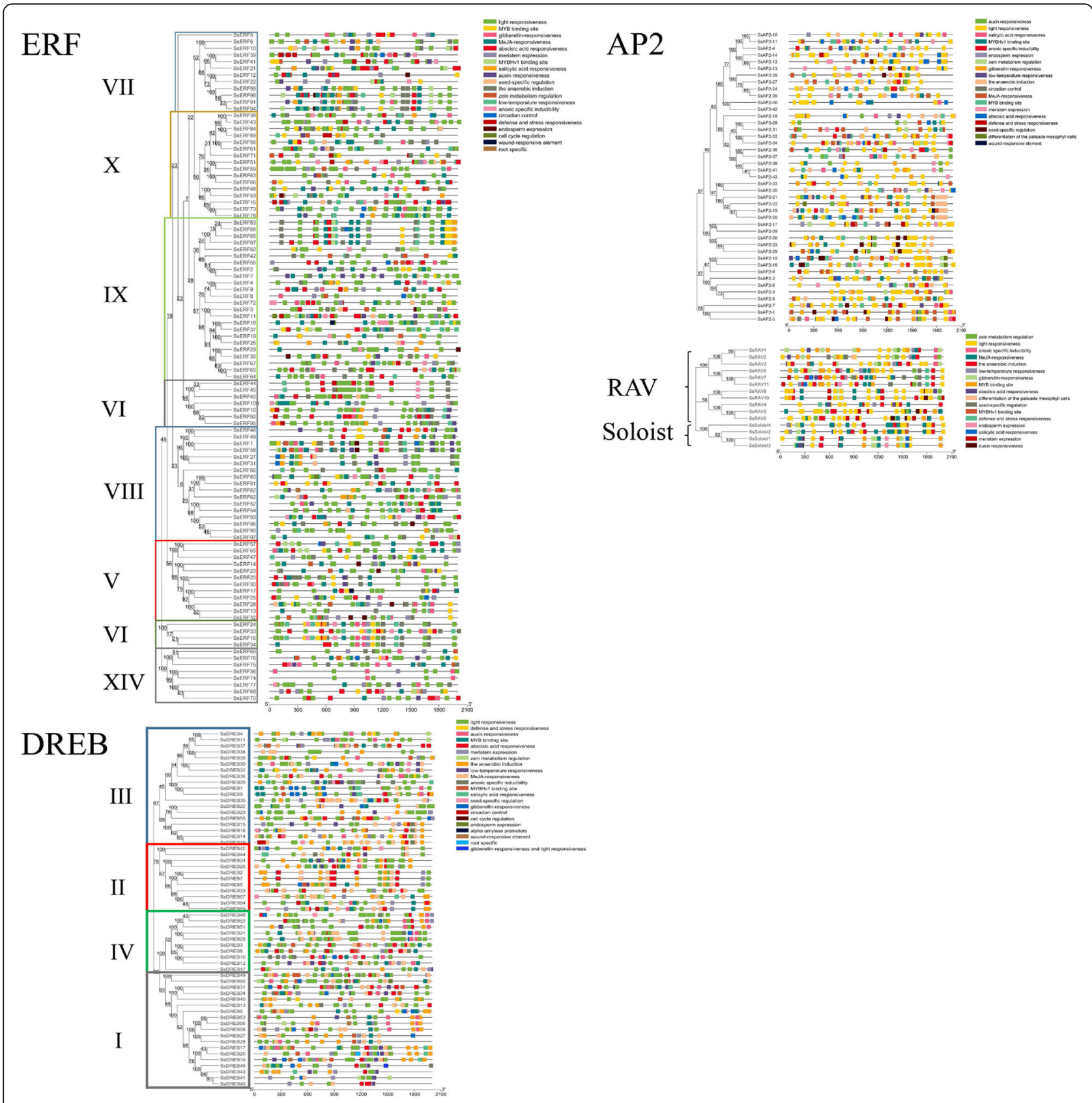

Fig. 7 Cis-acting elements and phylogenetic trees in the promoter region of the sugarcane AP2/ERF genes. The 2000 bp promoter region upstream of the gene was analyzed. Different colored boxes represent different cis-acting elements

these results, ERF and RAV gene differentiation might occur later in S. spontaneum evolution.

Syntenic analysis of $A P 2 / E R F$ was carried out to discover the evolutionary relationship of the SsAP2/ERF genes in five monocotyledonous plants (O. sativa, S. bicolor, T. aestivum, Z. mays, S. spontaneum) and one dicotyledonous plant (A. thaliana). In this analysis, SsAP2/ $E R F$ genes had higher homology with $A P 2 / E R F$ genes from the four kinds of grass and less homology with Arabidopsis. More homologous genes between sugarcane and wheat are likely due to the larger genome size and gene number in wheat [38]. By analyzing the homology of SsAP2/ERF and S. bicolor AP2/ERF genes, we found that 168 SsAP2/ERF genes likely existed before the number of $S$. spontaneum chromosomes was reduced from 10 to 8. Also, 63-70\% of identified SsAP2/ ERF genes were homologous in sorghum (168), rice (147), maize (139), and wheat (145). This finding indicated that the $A P 2 / E R F$ family in different plants might have evolved from a common ancestor. 


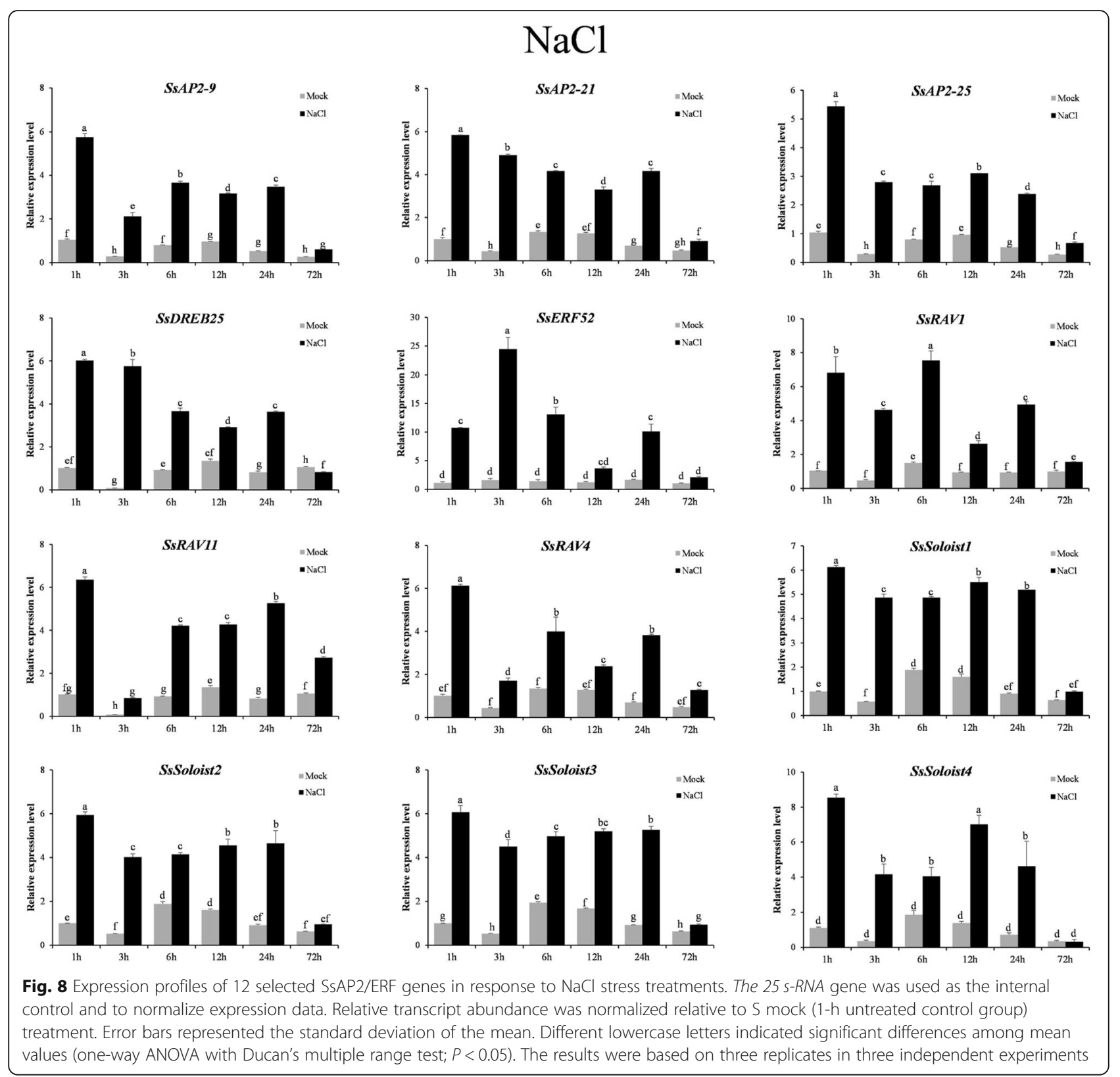

Due to the plasticity of the $A P 2 / E R F$ genes and individual family members' specificity, members of this family were likely to be important targets for genetic engineering and breeding to improve crops [39]. The gene expression patterns are essential for the prediction of gene function prediction. Analysis of tissue- and growth stage-specific expression showed that SsAP2/ $E R F \mathrm{~s}$ were widely expressed in sugarcane at the seedling stage and leaves during early maturity and the mature stage and in different stem segments, indicating that these genes played essential roles in sugarcane growth and development. DREB family genes in group I was highly expressed in leaves at all development stages and in three stem segments, suggesting that these genes might be involved across the entire development process of sugarcane leaves and stems. The expression levels of 29 SsAP2/ERF genes in stems during the seedling stage were lower than those in the early maturity stage and mature stage. Among them, 28 were members of the DREB and ERF family, which might be related to sugar accumulation in the sugarcane stem and consistent with previous studies for other plants. For example, compared with wild rice, transgenic rice carrying the ERF protein TSRF1 had $30-60 \%$ increases in proline and soluble sugar content that could enhance the osmotic tolerance of rice [40].

Earlier studies of $A P 2 / E R F$ family genes in other plants emphasized their role in response to hormonal and 
abiotic stresses. OsEREBP1 attenuates disease caused by $X O o$ and confers drought and submergence tolerance in transgenic rice [41]. Induction of the AP2/ERF transcription factor CRL5 promoted crown root initiation by inhibiting cytokinin signaling [42]. In the present study, the expression patterns of 12 SsAP2/ERF genes in response to $\mathrm{NaCl}, \mathrm{PEG6000}, \mathrm{ABA}$, and GA treatments suggested that these genes had essential roles in abiotic stress and hormone responses sugarcane. qRT-PCR verification revealed that the expressions of these 12 SsAP2/ERF genes distributed across the five subfamilies were significantly induced by $\mathrm{NaCl}$ treatment, similar to other species' findings, including the increase in expression of the $A P 2 / E R F$ family gene CAP2 in chickpeas and soybeans exposed to salt stress [43]. GmERF7 expression increased salt tolerance in tomato [44], whereas the pepper pathogen-induced transcription factor $R A V_{1}$ played a vital role in bacterial salt stress tolerance [45]. Here we showed that the expression of SsERF52 was up-regulated by up to 15 -fold after $\mathrm{NaCl}$ treatment. This gene had the highest homology with the wheat salt-responsive gene, TaERF4 [46]. Like TaERF4 in wheat, SsERF52 expression was not induced by exogenous abscisic acid (ABA). Overexpression of the Arabidopsis AP2/ERF gene HARD $Y$ improved drought tolerance by reducing the transpiration of transgenic Trifolium alexandrinum L [47]. Drought stress induced expression of the DERB OsAP21 in rice [48], and here we found that expression of 12 SsAP2/ERF genes was induced at $3 \mathrm{~h}$ after PEG6000 treatment. The expression level of SsERF52 after PEG6000 treatment was opposite that after $\mathrm{NaCl}$ treatment, with inhibition of gene expression at several time points. Multiple lines of evidence indicated that genes expressed during dehydration and salt stress responses in plants partially overlapped. For example, transgenic plants that overexpressed Arabidopsis OsMYB3R-2 have enhanced cold tolerance, drought tolerance, and salt tolerance [49]. Increasing amounts of evidence showed that $A P 2 / E R F$ genes were regulated by hormones such as $\mathrm{ABA}$ and GA, and thus these genes played an essential role in hormone signaling networks [50]. In the present study, promoter analysis indicated that most SsAP2/ERF genes' promoter regions contained multiple cis-acting elements related to ABA responses. qRT-PCR analysis of the 12 selected SsAP2/ERF genes showed that, except for SsERF52, expressions of these genes were induced by ABA. AP2 / ERF genes played an active role in ABAmediated stress response, a critical hormone that regulated abiotic stress responses (including drought, salinity, cold, and heat stress) [50]. For example, ANT [51] in Arabidopsis was induced by ABA to up-regulate genes containing DRE and ABRE elements. ANT is homologous to SsAP2-21, indicating that SsAP2/ERF genes might regulate abiotic stress through ABA-dependent pathways. After exogenous GA treatment, the expression levels of SsRAV4, SsRAV11, SsDREB25, and SsAP2-25 were not affected, but GA induced other genes' expression. Our research indicated that some SsAP2/ERF genes were differentially expressed under various abiotic stresses and hormone treatments compared with the control group, suggesting that this gene family was essential for environmental adaptation. In particular, the expression patterns of some SsAP2/ERF genes and their homologs varied. For example, the SsSoloist 4 gene expression was induced to varying degrees by the four stress treatments. These expression patterns differed from those for its Arabidopsis homolog At4g13040, an active regulator of disease defenses, and induced by SA treatment. However, the expression of this gene was inhibited by low temperature and salt stress. Given the antagonistic roles of $\mathrm{SA}$ and $\mathrm{ABA}$ in plant defense, At4g13040 expression may have opposing effects in response to ABA and SA treatment. Compared with the control group, SsSoloist4 expression was up-regulated after $3 \mathrm{~h}$ of ABA treatment, indicating that this gene's regulation mechanism likely differed from that for At4g13040 under abiotic stress.

Therefore, it could be seen from the above experiments that $12 S s A P 2$ / ERF genes were induced and expressed by $\mathrm{NaCl}$ and PEG6000 in varying degrees. There were many CREs related to ABA response in the promoter region of these genes, such as ABRE, and more than one copy, which meaned that their fast-induced expression on exogenous ABA treatment might also be mediated by themselves. A total of $12 A P 2$ / ERF genes were positively regulated by ABA, which further confirmed the result. Among the 12 AP2 / ERF genes, only SsAP2-21 had no CRE related to GA response. However, after GA treatment, the expression of 12 AP2 / ERF genes had no significant correlation with the number of TATC-box box, showing that gene expression was a complex biological process, regulated by many factors. The results also showed that the number of CREs were related to abiotic stress. Still, there was no significant correlation between CREs and 12 SsAP2/ERF genes' gene expression under dehydration and salt stress.

AP2 / ERF gene is regulated by ethylene and brassinosteroid when the plant exposed to salt, low temperature, and flooding stress [52]. AP2 / ERF, especially the ERF subfamily, plays a role as the primary downstream regulator of the ETH signaling pathway [52, 53]. For example, in Arabidopsis, EIN3 activate ERF1, $E S E$, and their downstream stress-related genes, promoting salt tolerance. ETH signal transduction is a necessary condition for plant salt tolerance [54]. However, ethylene's regulation to stress through AP2 / ERF is very complex, which needs further study. BRs also plays a vital role in the abiotic stress response of plants [55]. Recent studies have shown that $A P 2 / E R F$ gene is involved 
in regulating BRs on drought stress and plant growth [56]. BRs signal negatively regulates DREB gene TINY through the phosphorylation of BIN2, and TINY positively regulates drought response and inhibits BRs mediated plant growth through the antagonistic effect of TINY-BES1. These findings provide useful insight to study the relationship between SsAP2 / ERF and BRs in the future. Plants will inevitably suffer from oxidative stress when subjected to biotic and abiotic stresses [57]. The change of oxidation balance might be complex and hurt plants. AP2 / ERF gene is involved in the regulation of oxidative stress response in plants [58]. Oxidative stress strongly induced the ERF gene SICRF1 in tomato [59]. Cytokinin response factor 6 (CRF6) in Arabidopsis played a negative role in oxidative stress response, indicating that the cytokinin mediated the oxidative stress response regulated by $A P 2$ / ERF gene [60]. However, the mechanism of plant response to abiotic stress, including oxidative stress, is still unclear. Sugarcane response to oxidative stress-mediated by SsAP2 / ERF genes is needed for further research in the future. Our results could provide a foundation for identifying novel candidate $A P 2 / E R F$ genes as targets for genetic engineering of novel sugarcane germplasm that will produce plants with enhanced tolerance of abiotic stresses.

\section{Conclusions}

This study comprehensively analyzed the supergene family of sugarcane AP2 / ERF. The 218 identified AP2 / ERF superfamily genes were classified in detail. Their evolutionary characteristics, expression patterns in different sugarcane tissues and growth stages, and their response to abiotic stress and hormones were studied. These results provided valuable resources to understand better the biological role of the sugarcane AP2 / ERF genes.

\section{Methods \\ Identification and classification of members AP2/ERF superfamily genes in sugarcane}

The genome sequences and the sequence information of sugarcane were downloaded from the S. spontaneum AP85-441 genome (http://www.life.illinois.edu/ming/ downloads/Spontaneum_genome/) [31]. The protein sequences of AP2/ERF superfamily genes in rice and Arabidopsis were collected from the NCBI (https://www.ncbi. nlm.nih.gov/). These proteins were used as query sequences in the local BLAST program (Basic Local Alignment Search Tool) to find members of AP2/ERF superfamily genes of the sugarcane genome with the following parameters: expected values $\leq 1 \mathrm{E}-5$. All BLAST hits were checked and searched for conserved AP2 domains online using the Search Pfam feature of the Pfam (https:// pfam.xfam.org/) website under default parameters. In addition, the results of Pfam were verified again using the
NCBI CDD tool (https://www.ncbi.nlm.nih.gov/Structure/ bwrpsb/bwrpsb.cgi/) and the cutoff set to 0.01 .

\section{Phylogenetic analysis of sugarcane AP2/ERF genes}

Multiple alignments of candidate $A P 2 / E R F$ genes were performed to explore the phylogenetic relationship of sugarcane $A P 2 / E R F$ genes using ClustalW [61] with default parameters. The results were used to construct phylogenetic trees by the neighbor-joining method and were then visualized using MEGA 6.0 software [62]. The phylogenetic trees were generated using complete protein sequences with the following parameters: pair-wise deletion, Poisson correction, and 1000 bootstrap replicate.

\section{Gene structure and conserved motif analyses}

Conserved motifs of AP2/ERF proteins were identified using the online tool Multiple Em for Motif Elicitation (MEME) version 5.0 .5 [63] (http://meme-suite.org/tools/meme/) with the following parameters: (1) the number of occurrences of a single motif distributed among the sequences within the model was set to zero or one per sequence; (2) the maximum number of motifs found was set as 25 ; (3) the optimum motif width was set to $\geq 6$ and $\leq 50$; and (4) motifs with a matched E-value should be below 0.05 . Gene structure was investigated using GSDS 2.0 (http://gsds.cbi.pku.edu.cn/) [64]. We used TBtools software [65] to integrate phylogenetic trees, conserved motifs, and gene structure results.

\section{Chromosomal distribution and duplication analysis of AP2/ERF superfamily genes}

The chromosomal distribution information of the identified genes was searched against the reference sugarcane genome database, and the results obtained were visualized using TBtools software. Analysis of gene Duplication events using Multiple collinear scanning toolkits (MCScanX) [66]. The syntenic relationship between the SsAP2/ERF genes and AP2/ERF genes from selected plants was determined by using Dual Synteny Plotter software (https://github.com/CJ-Chen/TBtools/). The putative duplication events were detected for the AP2/ $E R F$ genes. Tandem duplication was identified as two proteins with a greater than $40 \%$ similarity and separated by four or fewer gene loci; others were identified as segmental duplications, separated by more than five genes. Non-synonymous (ka) and synonymous (ks) substitution of each duplicated AP2/ERF genes were calculated using KaKs_Calculator 2.0 [67]. The divergence time $(\mathrm{T})$ was calculated by $\mathrm{T}=\mathrm{Ks} /\left(2 \times 6.1 \times 10^{-9}\right) \times 10^{-6}$ Mya [68] These results were visualized using TBtools.

\section{Analysis of cis-acting elements of AP2/ERF superfamily genes}

Two thousand bp upstream of the transcriptional start site of each SsAP2/ERF gene was selected to inspect potential CREs. 
They were submitted to the PlantCARE website (http://bioinformatics.psb.ugent.be/webtools/plantcare/html/).

\section{Transcriptome data source and bioinformatic analysis} Sugarcane tissue-specific expression data included leaves and stems at the seedling stage of 35 days and the early maturity stage of 9 months and the maturity stage of 12 months (Additional file 14). All SsAP2 / ERF FPKMs (Segmentals Per Kilobase of transcript per Million segmental mapped) was used to make heat maps and cluster analysis through TBtools.

\section{Plant materials}

Sugarcane variety ROC22 is from Guangxi University, Guangxi, China. All the materials were cultured in Murashige and Skoog's medium containing 3\% sucrose and $0.7 \%$ agar until seedling stage [69]. The seedlings were then transplanted to the greenhouse with light intensity of $100 \mu \mathrm{mol} / \mathrm{m}$-2S-1, light cycle of 16:8-h (light / dark), temperature of $28^{\circ} \mathrm{C}$, and treated with hormone at 5-7 leaf stage and simulated abiotic stresses. Hormonal treatment was sprayed with abscisic acid (ABA, $100 \mu \mathrm{M})$ and gibberellin (GA, $100 \mu \mathrm{M})$. Abiotic stress treatment was irrigated with $\mathrm{NaCl}(250 \mathrm{mM})$ to simulate salt stress, and PEG6000 (20\%) was used to simulate dehydration stress. All the young leaves were taken for samples with the time points are $1,3,6,12,24$, and $72 \mathrm{~h}$. The collected samples were quickly placed in liquid nitrogen and stored in a $80^{\circ} \mathrm{C}$ refrigerator for subsequent RNA extraction.

\section{Quantitative real-time PCR (qRT-PCR) analysis}

Each qRT-PCR reaction mixture $(20 \mu \mathrm{L})$ comprised of $10 \mu \mathrm{L}$ Taq polymerase (SYBR Premix Ex TaqII; Takara), $2 \mu \mathrm{L}$ of each forward and reverse primers $(2 \mu \mathrm{M}), 2 \mu \mathrm{L}$ of cDNA, and $6 \mu \mathrm{L}$ of water. The RNA expression level was normalized to the level of 25S-rRNA expression. The amplification was conducted in LightCycler 96 RealTime PCR System (Roche Lightcyler ${ }^{\circ} 480$ ). A standard thermal profile for SYBR Premix was as followed: cDNA synthesis at $37^{\circ} \mathrm{C}$ for $15 \mathrm{~min}$ and enzyme inactivation at $85^{\circ} \mathrm{C}$ for $5 \mathrm{~s}$. qPCR conditions were: initial denaturation $95^{\circ} \mathrm{C}$ for 30s, denaturation $95^{\circ} \mathrm{C}$ for $5 \mathrm{~s}$, annealing and extension $60^{\circ} \mathrm{C}$ for $30 \mathrm{~s}$. Transcripts expression levels were calculated with the $2^{-\Delta \Delta \mathrm{Ct}}$ method, as previously mentioned in Livak and Schmittgen [70]. Primers used for this analysis are mentioned in Additional file 15.

\section{Data statistics}

All data were analyzed for variance using IBM SPSS Statistics. Statistical methods were used to compare the significance levels of LSD (least significant difference test, LSD) at 0.05 .

\section{Supplementary information}

Supplementary information accompanies this paper at https://doi.org/10. 1186/s12864-020-07076-X.

Additional file 1 List of the 218 SSAP2/ERF genes identified in this study. Additional file 2 Sequence analysis of 218 SSAP2 / ERF genes.

Additional file 3. Conserved domains of AP2/ERF superfamily proteins identified by HMMSCAN

Additional file 4. Multiple alignments of deduced amino acid sequences of the AP2/ERF and B3 DNA-binding domains of AP2/ERF superfamily proteins

Additional file 5 Gene structures of AP2/ERF superfamily genes. The exon/intron structure was visualized by the Gene Structure Display Server 2.0 (Visualized). The data of gene structure was based on the gene annotation model of $S$. spontaneum L. genome.

Additional file 6 Summary of motifs in AP2/ERF superfamily genes by MEME analysis.

Additional file $\mathbf{7}$ Chromosome distribution of AP2/ERF superfamily genes in the Saccharum spontaneum L. genome.

Additional file 8 Segmentally and tandemly duplicated SSAP2/ERF gene pairs.

Additional file 9. One-to-one orthologous relationships between sugarcane and other five plant species.

Additional file $\mathbf{1 0}$ List of cis-acting elements in the AP2 / ERF superfamily genes' promoter region.

Additional file 11 RNA-seq data of 218 SSAP2/ERF genes that were used in this study.

Additional file 12. Tissue-specific expression profile of AP2 / ERF gene in sugarcane.

Additional file 13 Expression profiles of 12 selected SSAP2/ERF genes in response to various abiotic stress treatments and hormone treatments.

Additional file 14. Sugarcane tissue-specific expression data.

Additional file 15. Sequences of the primers used in this study.

\section{Abbreviations}

S. spontaneum: Saccharum spontaneum L; SSAP2/ERF: Sugarcane AP2/ERF; SsChr: Saccharum spontaneum chromosome; FPKM: Segmentals Per Kilobase of transcript per Million segmental mapped; A4: Ancestral chromosome A4; ABA: Abscisic acid; GA: Gibberellins; PEG: Polyethylene Glycol; SA: Salicylic acid; Xoo: Xanthomonas oryzae pv. Oryzae; ETH: Ethylene; BRs: Brassinosteroids

\section{Acknowledgments}

The authors thank lab members for their assistance.

\section{Authors' contributions}

PTL and ZC performed the experiments. CHH, PPL, GQH, LNX, ZHD analyzed the data. PTL wrote the manuscript. XYZ, YZ, and MQZ designed the study and revised the manuscript. The authors have read and approved the final manuscript.

\section{Funding}

This study was supported by the National Natural Science Foundation of China (31801423 and 31771863), Open Foundation of State Key Laboratory for the Protection and Utilization of Subtropical Agricultural Biological Resources (SKLCUSA-b201708, SKLCUSA-a201912, and SKLCUSA-b201806), earmarked fund for Modern Agriculture Technology of China (CARS-170106) and Special Fund for Science and Technology Innovation of Fujian Agriculture and Forestry University (KFA17168A, KFA17525A, KFA17169A, 2018 N1002). The funders had no role in the study's design and collection, analysis, and interpretation of data and in writing the manuscript.

Availability of data and materials

All data generated or analyzed during this study are included in this published article and its supplementary information files (from Additional file 1 to Additional file 15). The genome sequences and the sequence 
information of sugarcane were downloaded from the S. spontaneum AP85441 genome (http://www.life.illinois.edu/ming/downloads/Spontaneum_ genome/)

\section{Ethics approval and consent to participate}

The sugarcane materials used in the experiment were supplied by the sugarcane clonal germplasm repository of Guangxi University. These plant materials are widely used worldwide, and no permits were required for the collection of plant samples. This article did not contain any studies with human participants or animals and did not involve any endangered or protected species.

\section{Consent for publication}

Not applicable.

\section{Competing interests}

The authors declare that they have no competing interests.

\section{Author details}

${ }^{1}$ National Engineering Research Center for Sugarcane \& Guangxi Key Laboratory for Sugarcane Biology, Fujian Agriculture and Forestry University, Fuzhou 350002, China. ${ }^{2}$ State Key Laboratory for Conservation and Utilization of Subtropical Agro-Biological Resources \& Guangxi Key Laboratory for Sugarcane Biology, Guangxi University, Nanning 530005, China. ${ }^{3}$ Fujian Provincial Key Laboratory of Plant Functional Biology, College of Life Sciences, Fujian Agriculture and Forestry University, Fuzhou 350002, China. ${ }^{4}$ Key Laboratory of Sugarcane Biology and Genetic Breeding Ministry of Agriculture, Fujian Agriculture and Forestry University, Fuzhou 350002, China.

Received: 26 March 2020 Accepted: 16 September 2020 Published online: 02 October 2020

\section{References}

1. Wang $H$, Wang $H$, Shao $H$, Tang X. Recent advances in utilizing transcription factors to improve plant abiotic stress tolerance by transgenic technology. Front Plant Sci. 2016;7:67. https://doi.org/10.3389/fpls.2016.00067.

2. Gong Z, Xiong L, Shi H, Yang S, Herrera-Estrella LR, Xu G, Chao DY, Li J, Wang PY, Qin F, et al. Plant abiotic stress response and nutrient use efficiency. Sci China Life Sci. 2020;63(5):635-74. https://doi.org/10.1007/ s11427-020-1683-x

3. Chinnusamy V, Schumaker K, Zhu JK. Molecular genetic perspectives on cross-talk and specificity in abiotic stress signalling in plants. J Exp Bot. 2004; 55(395):225-36. https://doi.org/10.1093/jxb/erh005.

4. Zhang JZ. Overexpression analysis of plant transcription factors. Curr Opin Plant Biol. 2003;6(5):430-40. https://doi.org/10.1016/s1369-5266(03)00081-5.

5. Debbarma J, Sarki YN, Saikia B, Boruah HPD, Singha DL, Chikkaputtaiah C. Ethylene response factor (ERF) family proteins in abiotic stresses and CRIS PR-Cas9 genome editing of ERFs for multiple abiotic stress tolerance in crop plants: a review. Mol Biotechnol. 2019;61(2):153-72. https://doi.org/10.1007/ s12033-018-0144-X

6. Xiang L, Liu C, Luo J, He L, Deng Y, Yuan J, Wu C, Cai Y. A tuber mustard AP2/ERF transcription factor gene, BjABR1, functioning in abscisic acid and abiotic stress responses, and evolutionary trajectory of the $A B R 1$ homologous genes in Brassica species. PeerJ. 2018;6:e6071. https://doi.org/ 10.7717/peerj.6071.

7. Zhu Q, Zhang J, Gao X, Tong J, Xiao L, Li W, Zhang H. The Arabidopsis AP2/ ERF transcription factor RAP2.6 participates in ABA, salt and osmotic stress responses. Gene. 2010;457(1-2):1-12. https://doi.org/10.1016/j.gene.2010.02. 011.

8. Nakano T, Suzuki K, Fujimura T, Shinshi H. Genome-wide analysis of the ERF gene family in Arabidopsis and rice. Plant Physiol. 2006;140(2):411-32. https://doi.org/10.1104/pp.105.073783.

9. El Ouakfaoui S, Schnell J, Abdeen A, Colville A, Labbe H, Han S, Baum B, Laberge S, Miki B. Control of somatic embryogenesis and embryo development by AP2 transcription factors. Plant Mol Biol. 2010;74(4-5):31326. https://doi.org/10.1007/s11103-010-9674-8.

10. Je BI, Piao HL, Park SJ, Park SH, Kim CM, Xuan YH, Park SH, Huang J, Do Choi $Y, A \cap G$, et al. RAV-Likel maintains brassinosteroid homeostasis via the coordinated activation of BR/1 and biosynthetic genes in rice. Plant Cell. 2010;2(6):1777-91. https://doi.org/10.1105/tpc.109.069575.
11. Li CW, Su RC, Cheng CP, Sanjaya YSJ, Hsieh TH, Chao TC, Chan MT. Tomato RAV transcription factor is a pivotal modulator involved in the AP2/EREBPmediated defense pathway. Plant Physiol. 2011;156(1):213-27. https://doi. org/10.1104/pp.111.174268.

12. Mizoi J, Shinozaki K, Yamaguchi-Shinozaki K. AP2/ERF family transcription factors in plant abiotic stress responses. Biochim Biophys Acta. 2012;1819(2): 86-96. https://doi.org/10.1016/j.bbagrm.2011.08.004.

13. Giri MK, Swain S, Gautam JK, Singh S, Singh N, Bhattacharjee L, Nandi AK. The Arabidopsis thaliana At4g13040 gene, a unique member of the AP2/ EREBP family, is a positive regulator for salicylic acid accumulation and basal defense against bacterial pathogens. J Plant Physiol. 2014;171(10):860-7. https://doi.org/10.1016/j.jplph.2013.12.015.

14. Imase A, Mitsuda N, Koyama T, Hiratsu K, Kojima M, Arai T, Inoue Y, Seki M, Sakakibara H, Sugimoto K, et al. The AP2/ERF transcription factor WIND1 controls cell dedifferentiation in Arabidopsis. Curr Biol. 2011;21(6):508-14. https://doi.org/10.1016/j.cub.2011.02.020.

15. Qi W, Sun F, Wang Q, Chen M, Huang Y, Feng YQ, Luo X, Yang J. Rice ethylene-response AP2/ERF factor OSEATB restricts internode elongation by down-regulating a gibberellin biosynthetic gene. Plant Physiol. 2011;157(1): 216-28. https://doi.org/10.1104/pp.111.179945.

16. Chung MY, Vrebalov J, Alba R, Lee J, McQuinn R, Chung JD, Klein P, Giovannoni J. A tomato (Solanum lycopersicum) APETALA2/ERF gene, SIAP2a, is a negative regulator of fruit ripening. Plant J. 2010;64(6):936-47. https:// doi.org/10.1111/j.1365-313X.2010.04384.X.

17. Licausi F, Giorgi FM, Zenoni S, Osti F, Pezzotti M, Perata P. Genomic and transcriptomic analysis of the AP2/ERF superfamily in Vitis vinifera. BMC Genomics. 2010;11:719. https://doi.org/10.1186/1471-2164-11-719.

18. Zhang Z, Li X. Genome-wide identification of AP2/ERF superfamily genes and their expression during fruit ripening of Chinese jujube. Sci Rep. 2018; 8(1):15612. https://doi.org/10.1038/s41598-018-33744-w.

19. Fan ZQ, Kuang JF, Fu CC, Shan W, Han YC, Xiao YY, Ye YJ, Lu WJ, Lakshmanan $\mathrm{P}$, Duan XW, et al. The banana transcriptional repressor MaDEAR1 negatively regulates cell Wall-modifying genes involved in fruit ripening. Front Plant Sci. 2016;7:1021. https://doi.org/10.3389/fpls.2016. 01021.

20. Serra TS, Figueiredo DD, Cordeiro AM, Almeida DM, Lourenço T, Abreu IA Sebastián A, Fernandes L, Contreras-Moreira B, Oliveira MM, et al. OsRMC, a negative regulator of salt stress response in rice, is regulated by two AP2/ ERF transcription factors. Plant Mol Biol. 2013;82(4-5):439-55. https://doi.org/ 10.1007/s11103-013-0073-9.

21. Wang C-T, Dong Y-M. Overexpression of maize ZmDBP3 enhances tolerance to drought and cold stress in transgenic Arabidopsis plants. Biologia. 2009; 64(6):1108. https://doi.org/10.2478/s11756-009-0198-0.

22. Bao S-G, Shi J-X, Luo F, Ding B, Hao J-Y, Xie X-D, Sun S-J. Overexpression of Sorghum WINL1 gene confers drought tolerance in Arabidopsis thaliana through the regulation of cuticular biosynthesis. Plant Cell Tissue Organ Cult. 2017;128(2):347-56. https://doi.org/10.1007/s11240-016-1114-2.

23. Licausi F, Ohme-Takagi M, Perata P. APETALA2/ethylene responsive factor (AP2/ERF) transcription factors: mediators of stress responses and developmental programs. New Phytol. 2013;199(3):639-49. https://doi.org/ 10.1111/nph.12291.

24. Lee SY, Hwang EY, Seok HY, Tarte VN, Jeong MS, Jang SB, Moon YH. Arabidopsis AtERF71/HRE2 functions as transcriptional activator via cisacting GCC box or DRE/CRT element and is involved in root development through regulation of root cell expansion. Plant Cell Rep. 2015;34(2):223-31. https://doi.org/10.1007/s00299-014-1701-9.

25. Sazegari S, Niazi A, Ahmadi FS. A study on the regulatory network with promoter analysis for Arabidopsis DREB-genes. Bioinformation. 2015;11(2): 101-6. https://doi.org/10.6026/97320630011101.

26. Chen J, Xia X, Yin W. Expression profiling and functional characterization of a DREB2-type gene from Populus euphratica. Biochem Biophys Res Commun. 2009;378(3):483-7. https://doi.org/10.1016/j.bbrc.2008.11.071.

27. Grivet L, Arruda P. Sugarcane genomics: depicting the complex genome of an important tropical crop. Curr Opin Plant Biol. 2002;5(2):122-7. https://doi. org/10.1016/s1369-5266(02)00234-0.

28. Lam E, Shine J, Silva JD, Lawton M, Bonos S, Calvino M, Carrer H, Silva-Filho MC, Glynn N, Helsel Z. Improving sugarcane for biofuel: engineering for an even better feedstock. GCB Bioenergy. 2009;1(3):251-5.

29. Azevedo RA, Carvalho RF, Cia MC, Gratão PL. Sugarcane under pressure: An overview of biochemical and physiological studies of abiotic stress. Trop Plant Biol. 2011;4(1):42-51. https://doi.org/10.1007/s12042-011-9067-4. 
30. Manoj VM, Anunanthini P, Swathik PC, Dharshini S, Ashwin Narayan J, et al. Comparative analysis of glyoxalase pathway genes in Erianthus arundinaceus and commercial sugarcane hybrid under salinity and drought conditions. BMC Genomics. 2019;19(Suppl 9):986. https://doi.org/10.1186/s12864-018-5349-7.

31. Zhang J, Zhang X, Tang H, Zhang Q, Hua X, Ma X, Zhu F, Jones T, Zhu X, Bowers $J$, et al. Allele-defined genome of the autopolyploid sugarcane Saccharum spontaneum L. Nat Genet. 2018;50(11):1565-73. https://doi.org/ 10.1038/s41588-018-0237-2

32. Wang P, Moore BM, Panchy NL, Meng F, Lehti-Shiu MD, Shiu SH. Factors influencing gene family size variation among related species in a plant family, Solanaceae. Genome Biol Evol. 2018;10(10):2596-613. https://doi.org/ 10.1093/gbe/evy193.

33. Du H, Huang M, Zhang Z, Cheng S. Genome-wide analysis of the AP2/ERF gene family in maize waterlogging stress response. Euphytica. 2014;198(1): $115-26$.

34. Zhuang J, Cai B, Peng RH, Zhu B, Jin XF, Xue Y, Gao F, Fu XY, Tian YS, Zhao $W$, et al. Genome-wide analysis of the AP2/ERF gene family in Populus trichocarpa. Biochem Biophys Res Commun. 2008;371(3):468-74. https://doi. org/10.1016/j.bbrc.2008.04.087.

35. Zhuang J, Chen JM, Yao QH, Xiong F, Sun CC, Zhou XR, Zhang J, Xiong AS. Discovery and expression profile analysis of AP2/ERF family genes from Triticum aestivum. Mol Biol Rep. 2011;38(2):745-53. https://doi.org/10.1007/ s11033-010-0162-7.

36. Lin H, Zhu W, Silva JC, Gu X, Buell CR. Intron gain and loss in segmentally duplicated genes in rice. Genome Biol. 2006;7(5):R41. https://doi.org/10. 1186/gb-2006-7-5-r41.

37. Qiu YL, Cho Y, Cox JC, Palmer JD. The gain of three mitochondrial introns identifies liverworts as the earliest land plants. Nature. 1998:394(6694):671-4. https://doi.org/10.1038/29286.

38. Brenchley R, Spannagl M, Pfeifer M, Barker GL, D'Amore R, Allen AM, McKenzie N, Kramer M, et al. Analysis of the bread wheat genome using whole-genome shotgun sequencing. Nature. 2012:491(7426):705-10. https:// doi.org/10.1038/nature11650.

39. Xu ZS, Chen M, Li LC, Ma YZ. Functions and application of the AP2/ERF transcription factor family in crop improvement. J Integr Plant Biol. 2011; 53(7):570-85. https://doi.org/10.1111/j.1744-7909.2011.01062.x.

40. Quan R, Hu S, Zhang Z, Zhang H, Zhang Z, Huang R. Overexpression of an ERF transcription factor TSRF1 improves rice drought tolerance. Plant Biotechnol J. 2010;8(4):476-88. https://doi.org/10.1111/j.1467-7652.2009. 00492.x.

41. Jisha V, Dampanaboina L, Vadassery J, Mithöfer A, Kappara S, Ramanan R. Overexpression of an AP2/ERF type transcription factor OsEREBP1 confers biotic and abiotic stress tolerance in rice. PLoS One. 2015;10(6):e0127831. https://doi.org/10.1371/journal.pone.0127831.

42. Kitomi $Y$, Ito $H$, Hobo $T$, Aya $K$, Kitano $H$, Inukai $Y$. The auxin responsive AP2/ ERF transcription factor CROWN ROOTLESS5 is involved in crown root initiation in rice through the induction of OsRR1, a type-a response regulator of cytokinin signaling. Plant J. 2011;67(3):472-84. https://doi.org/ 10.1111/j.1365-313X.2011.04610.x.

43. Shukla RK, Raha S, Tripathi V, Chattopadhyay D. Expression of CAP2, an APET ALA2-family transcription factor from chickpea, enhances growth and tolerance to dehydration and salt stress in transgenic tobacco. Plant Physiol. 2006;142(1):113-23. https://doi.org/10.1104/pp.106.081752.

44. Zhai Y, Wang Y, Li Y, Lei T, Yan F, Su L, Li X, Zhao Y, Sun X, Li J, et al. Isolation and molecular characterization of GMERF7, a soybean ethyleneresponse factor that increases salt stress tolerance in tobacco. Gene. 2013; 513(1):174-83. https://doi.org/10.1016/j.gene.2012.10.018.

45. Sohn KH, Lee SC, Jung HW, Hong JK, Hwang BK. Expression and functional roles of the pepper pathogen-induced transcription factor RAV1 in bacterial disease resistance, and drought and salt stress tolerance. Plant Mol Biol. 2006;61(6):897-915. https://doi.org/10.1007/s11103-006-0057-0.

46. Dong W, Ai X, Xu F, Quan T, Liu S, Xia G. Isolation and characterization of a bread wheat salinity responsive ERF transcription factor. Gene. 2012;511(1): 38-45. https://doi.org/10.1016/j.gene.2012.09.039.

47. Abogadallah GM, Nada RM, Malinowski R, Quick P. Overexpression of HARD $Y$, an AP2/ERF gene from Arabidopsis, improves drought and salt tolerance by reducing transpiration and sodium uptake in transgenic Trifolium alexandrinum L. Planta. 2011;233(6):1265-76. https://doi.org/10.1007/s00425011-1382-3

48. Jin X, Xue Y, Wang R, Xu R, Bian L, Zhu B, Han H, Peng R, Yao Q. Transcription factor OSAP21 gene increases salt/drought tolerance in transgenic Arabidopsis thaliana. Mol Biol Rep. 2013;40(2):1743-52. https:// doi.org/10.1007/s11033-012-2228-1.

49. Dai $X, X u$ Y, Ma Q, Xu W, Wang T, Xue Y, Chong K. Overexpression of an R1R2R3 MYB gene, OSMYB3R-2, increases tolerance to freezing, drought, and salt stress in transgenic Arabidopsis. Plant Physiol. 2007;143(4):1739-51. https://doi.org/10.1104/pp.106.094532.

50. Xie Z, Nolan TM, Jiang H, Yin Y. AP2/ERF transcription factor regulatory networks in hormone and abiotic stress responses in Arabidopsis. Front Plant Sci. 2019;10:228. https://doi.org/10.3389/fpls.2019.00228.

51. Meng LS, Wang ZB, Yao SQ, Liu A. The ARF2-ANT-COR15A gene cascade regulates $A B A$-signaling-mediated resistance of large seeds to drought in Arabidopsis. J Cell Sci. 2015;128(21):3922-32. https://doi.org/10.1242/jcs. 171207.

52. Kazan K. Diverse roles of jasmonates and ethylene in abiotic stress tolerance. Trends Plant Sci. 2015;20(4):219-29. https://doi.org/10.1016/j. tplants.2015.02.001.

53. Müller M, Munné-Bosch S. Ethylene response factors. A key regulatory hub in hormone and stress signaling. Plant Physiol. 2015;169(1):32-41. https:// doi.org/10.1104/pp.15.00677.

54. Tao JJ, Chen HW, Ma B, Zhang WK, Chen SY, Zhang JS. The role of ethylene in plants under salinity stress. Front Plant Sci. 2015;6:1059. https://doi.org/10. 3389/fpls.2015.01059.

55. Ye H, Liu S, Tang B, Chen J, Xie Z, Nolan TM, Jiang H, Guo H, Lin HY, Li L, et al. RD26 mediates crosstalk between drought and brassinosteroid signalling pathways. Nat Commun. 2017;8:14573. https://doi.org/10.1038/ ncomms14573.

56. Xie Z, Nolan T, Jiang H, Tang B, Zhang M, Li Z, Yin Y. The AP2/ERF transcription factor TINY modulates Brassinosteroid-regulated plant growth and drought responses in Arabidopsis. Plant Cell. 2019;31(8):1788-806. https://doi.org/10.1105/tpc.18.00918.

57. Generozova IP, Maevskaya SN, Shugaev AG. The inhibition of mitochondrial metabolic activity in etiolated pea seedlings under water stress. Russ J Plant Physiol. 2009;56(1):38-44. https://doi.org/10.1134/S1021443709010063.

58. Zhang H, Li A, Zhang Z, Huang Z, Lu P, Zhang D, Liu X, Zhang ZF, Huang R. Ethylene response factor TERF1, regulated by ETHYLENE-INSENSITIVE3-like factors, functions in reactive oxygen species (ROS) scavenging in tobacco (Nicotiana tabacum L.). Sci Rep. 2016;6:29948. https://doi.org/10.1038/ srep29948.

59. Shi X, Gupta S, Rashotte AM. Characterization of two tomato AP2/ERF genes, SICRF1 and SICRF2 in hormone and stress responses. Plant Cell Rep. 2014;33(1):35-45. https://doi.org/10.1007/s00299-013-1510-6.

60. Zwack PJ, De Clercq I, Howton TC, Hallmark HT, Hurny A, Keshishian EA, Parish AM, Benkova E, Mukhtar MS, Van Breusegem F, et al. Cytokinin response factor 6 represses Cytokinin-associated genes during oxidative stress. Plant Physiol. 2016;172(2):1249-58. https://doi.org/10.1104/pp.16. 00415.

61. Larkin MA, Blackshields G, Brown NP, Chenna R, McGettigan PA, McWilliam H, Valentin F, Wallace IM, Wilm A, Lopez R, et al. Clustal W and Clustal X version 2.0. Bioinformatics. 2007;23(21):2947-8. https://doi.org/10.1093/ bioinformatics/btm404.

62. Tamura K, Stecher G, Peterson D, Filipski A, Kumar S. MEGA6: molecular evolutionary genetics analysis version 6.0. Mol Biol Evol. 2013;30(12):2725-9. https://doi.org/10.1093/molbev/mst197.

63. Bailey TL, Boden M, Buske FA, Frith M, Grant CE, Clementi L, Ren J, Li WW, Noble WS. MEME SUITE: tools for motif discovery and searching. Nucleic Acids Res. 2009;37(Web Server issue):W202-8. https://doi.org/10.1093/nar/ gkp335.

64. Hu B, Jin J, Guo AY, Zhang H, Luo J, Gao G. GSDS 2.0: an upgraded gene feature visualization server. Bioinformatics. 2015;31(8):1296-7. https://doi. org/10.1093/bioinformatics/btu817.

65. Chen $\mathrm{C}$, Chen H, Zhang Y, Hannah R, Margaret H, Yehua H, Rui X. TBtools: an integrative toolkit developed for interactive analyses of big biological data. Mol Plant. 2020;13(8):1194-202. https://doi.org/10.1016/j.molp.2020.06.009.

66. Wang Y, Tang H, Debarry JD, Tan X, Li J, Wang X, Lee TH, Jin H, Marler B, Guo H, et al. MCScanX: a toolkit for detection and evolutionary analysis of gene synteny and collinearity. Nucleic Acids Res. 2012;40(7):e49. https://doi. org/10.1093/nar/gkr1293.

67. Wang D, Zhang Y, Zhang Z, Zhu J, Yu J. KaKs calculator 2.0: a toolkit incorporating gamma-series methods and sliding window strategies. Genomics Proteomics Bioinformatics. 2010;8(1):77-80. https://doi.org/10. 1016/s1672-0229(10)60008-3 
68. Lynch M. The evolutionary fate and consequences of duplicate genes. Science. 2000;290(5494):1151-5.

69. Ijaz S, Rana IA, Khan IA, Saleem M. Establishment of an in vitro regeneration system for genetic transformation of selected sugarcane genotypes. Genet Mol Res. 2012;11(1):512-30. https://doi.org/10.4238/2012.

70. Livak KJ, Schmittgen TD. Analysis of relative gene expression data using real-time quantitative PCR and the $2-\Delta \Delta C T$ method. Methods. 2001;25(4): $402-8$.

\section{Publisher's Note}

Springer Nature remains neutral with regard to jurisdictional claims in published maps and institutional affiliations.

- fast, convenient online submission

- thorough peer review by experienced researchers in your field

- rapid publication on acceptance

- support for research data, including large and complex data types

- gold Open Access which fosters wider collaboration and increased citations

- maximum visibility for your research: over $100 \mathrm{M}$ website views per year

At BMC, research is always in progress. 